\title{
Jobof

\section{Leo Lo: Research and Development Librarian at Kansas State University}

In 2010, Kansas State University (KSU) Libraries underwent a major reorganization with the goal of becoming a user-centered and data-driven organization. In June of that year, Leo Lo transitioned from his position as multicultural studies librarian to the newly created position of research and development (R\&D) librarian.

The R\&D librarian position falls under the new Office of Library Planning and Assessment, which also includes a director, library data coordinator, and service quality librarian. While the goal of the office is to provide centralized data collection, assessment, and product development, Lo has specialized responsibilities focused on researching adaptable organization structures, business models, and successful innovations in academic libraries; improving internal

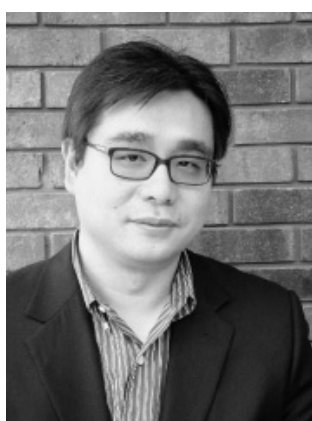

Leo Lo of assessment. It also assures the rest of the library and, more broadly, the institution, that assessment is not just being done for the sake of doing assessment, but that there is an end product. Such a position demonstrates that KSU Libraries embrace adventure and a willingness to take risks, essential qualities to create an environment that encourages innovation.

While some of what Lo does involves new technology (he is currently working with the mobile site team on making KSU Libraries' resources mobile friendly), he is also engaged in nontech based projects like the Reference Training Boot Camp, which aims to assess and define the value of library reference services. "As these are experiments, we don't expect all of them to succeed. The value is processes; developing new products, services, and practices; and creating collaborations with campus units and other libraries.

"Somewhat similar in concept to a R\&D department in a corporation, my job is to come up and experiment with new products and services based on assessment results. The key word here is experiment," said Lo in a recent interview.

Although assessment-related positions are becoming more common in academic libraries, some initiatives end there without the important step of evidence-based action. Lo's R\&D position ensures that there is a mechanism in place to act on the results in the trial and error and learning more about us and our users in the process, before fully committing scarce resources," said Lo.

Another unique project is the K-State Libraries Undergraduate Diversity Fellowship, initiated by Lo to help promote diversity at KSU, increase the diversity of the library workforce, and help recruit diverse students to the profession by introducing librarianship to them early on. The project is still in the development stage, but the general idea is

Erin Dorney is outreach librarian at Millersville University of Pennsylvania. Have a story idea for Job of a Lifetime? E-mail Erin Dorney at erin.dorney@millersville.edu. 
for the Fellows to work closely with librarian mentors on meaningful projects, helping them to gain a better understanding of what the profession is about and opening a potential career path.

In addition to his MSLIS, Lo holds an MFA in screenwriting from Hollins University (Virginia). "On the surface, that doesn't seem to have anything to do with librarianship. But understanding how to tell a story is actually extremely useful in presenting your ideas to others and persuading people to support your projects," said Lo.

His experience in screenwriting taught him how distill something very complicated, like a two-hour movie, into a one-sentence logline. This skill has been useful for pitching ideas, crafting engaging proposals, and framing captivating elevator speeches. Screenwriting skills have also been beneficial in the creation of engaging user videos, evidenced in Lo's recent article "Design Your Video Tutorial Like a Hollywood Blockbuster: Using Hollywood Screenplay Structure to
Engage Viewers," published in a special instructional design and technology issue of Indiana Libraries.

Lo encourages librarians to embrace curiosity, creativity, and a willingness to try new things, particularly if they are interested in getting into R\&D. Staying current with the newest trends, being excited by innovations, and not being afraid of failure are key. He also recommends gaining project management experience and being willing to work collaboratively.

When asked if being a R\&D librarian is his "job of a lifetime," Lo responded with a resounding yes. "It offers me opportunities to learn about the newest trends and innovations in librarianship; gives me plenty of creative freedom to work on cutting-edge projects; and allows me to collaborate with other forward-thinking people. I can't think of a better library job for me right now."

Lo writes about librarianship, film, and food on his blog www.leoslo.com and can be found on Twitter @leoslo. $\boldsymbol{n}$

\section{We play nice with others}
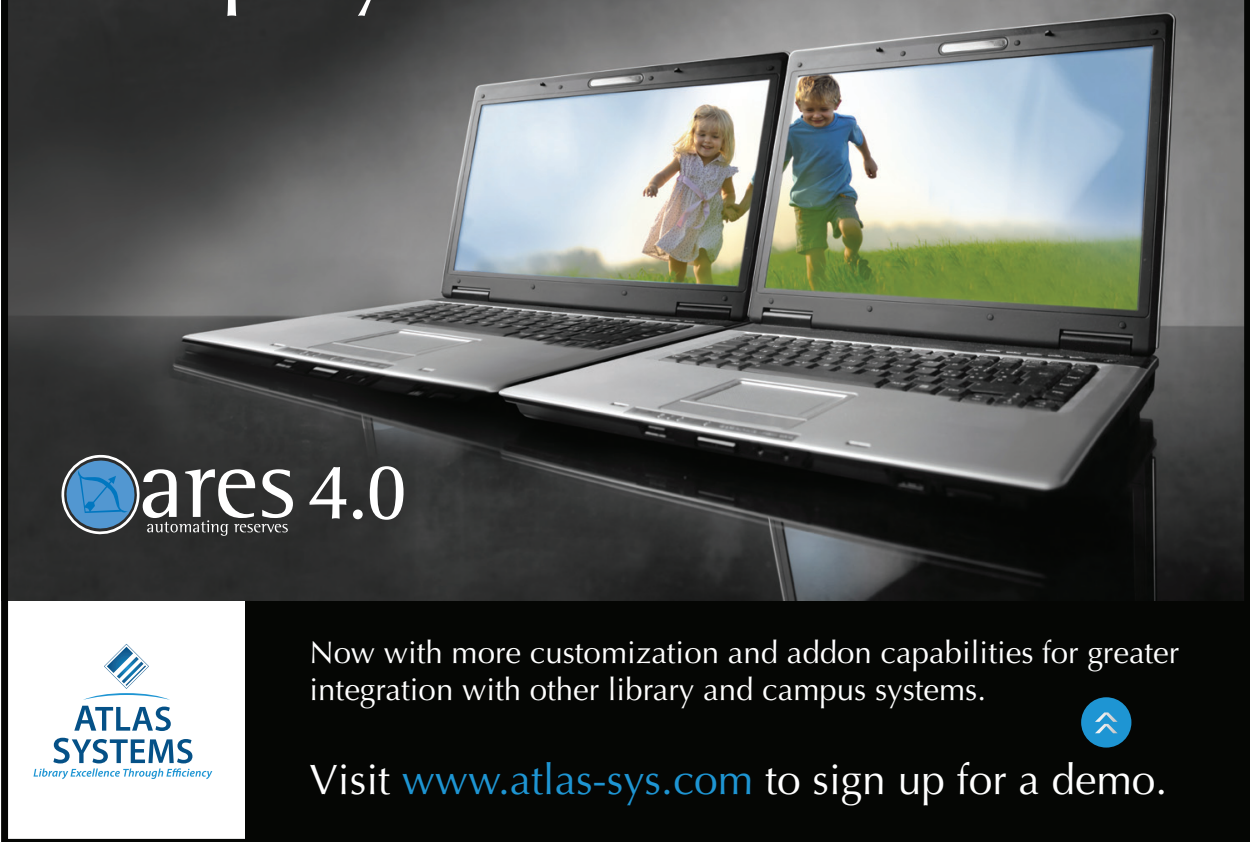

Now with more customization and addon capabilities for greater integration with other library and campus systems.

Visit www.atlas-sys.com to sign up for a demo. 